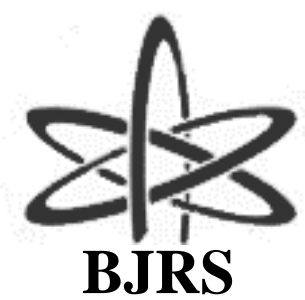

BRAZILIAN JOURNAL

$\mathrm{OF}$

RADIATION SCIENCES

03-01 (2015) 01-21

\title{
DNA damage evaluation in a nursing team occupationally exposed to ionizing radiation
}

\author{
I. Bortolotto ${ }^{\mathrm{a}, \mathrm{b}}$; A. P. S. Brum ${ }^{\mathrm{b}}$; L. M. Souza ${ }^{\mathrm{b}, \mathrm{c}}$; C. Trindade ${ }^{\mathrm{b}, \mathrm{d}}$; T. N. Guecheva ${ }^{\mathrm{b}}$; F. \\ M. Luiz ; A. L. L. Paula-Ramos ; A. R. Consiglio ${ }^{\mathrm{a}, \mathrm{b}}$ \\ a Programa de Pós-Graduação em Enfermagem, Universidade Federal do Rio Grande do Sul (UFRGS); \\ b Departamento de Biofísica, Instituto de Biociências, UFRGS; \\ c Programa de Pós-Graduação em Biologia Celular e Molecular, Centro de Biotecnologia, UFRGS; \\ d Programa de Pós-Graduação em Genética e Biologia Molecular, UFRGS; \\ CEP 91.501-970, Porto Alegre-RS, Brazil
}

arconsig@ufrgs.br

\begin{abstract}
To evaluate DNA damage in lymphocytes and cognitive deficits in a nursing team occupationally exposed to ionizing radiation in a university hospital in southern Brazil. Method: Cross-sectional study, case-control design, included 79 women working in a nursing team in Hemodynamics, Radiology, Ambulatory and Midwifery Units. They were classified in two groups: 1_Exposed to ionizing radiation, $\mathrm{n}=38$ (Hemodynamics and Radiology Units) and 2_Unexposed to ionizing radiation, $\mathrm{n}=41$ (Ambulatory and Midwifery Unit). Blood was collected and DNA damage in lymphocytes was analyzed using the comet assay and micronucleus test (MN). The cells were classified according to the damage frequency (DF) and index (DI) based on the comet tail size. Cognition was also evaluated according to the scores obtained in Stroop test, the digit and word span. No difference was found for the variables DI, DF, MN, Stroop_word, Stroop_color, Stroop_color/word between the groups. However, when the groups were analyzed independently of their exposure condition, the damage index in the Hemodynamics was lower than in all other Units. The damage frequency in Midwifery Unit was higher than in Ambulatory and Hemodynamics. The frequency of micronucleus was not different among the employees from the four Units. DNA damage in lymphocytes did not differ between nursing teams occupationally exposed or not exposed to ionizing radiation. However, higher damage in a non exposed group may indicate other risks to the healthcare team.
\end{abstract}

Keywords: DNA damage, Occupational, Radiation 


\section{INTRODUCTION}

The biological effects of ionizing radiation are well characterized for high dose exposures, such as those found, for example, in nuclear accidents and for therapeutic purpose. DNA damage may occur as a consequence of water radiolysis and the formation of free radicals. At low dose exposure, the current risk model, although still controversial (Brooks and Dauer, 2014), indicates that there is a non threshold risk of malignancy linearly related to the dose (UNSCEAR, 2008; BEIR, 2006). Cytogenetic studies have shown an increase in the frequency of chromosome aberrations in workers exposed to low doses of ionizing radiation when compared to those not exposed (Maluf et al, 2001, Martinez et al., 2010, Zakeri et al, 2010).

Low levels of low linear energy transfer ionizing radiation are found in x-rays and gamma rays up to about $100 \mathrm{mSv}$ (BEIR, 2006). In a health facility, the main sources of radiation are found in Nuclear Medicine, Radiology and Radiotherapy Units, as well as in Surgery or Interventional Rooms. The main emissions are beta particles, electrons, gamma or X-ray, that may come from radioisotopes, diagnostic x-ray, computer tomography or linear accelerators. The employees who work in these areas are potentially exposed to radiation, and attitudes of radioprotection are mandatory to minimize the risk of injury. In general, those who work in an environment of diagnostic or therapeutic radiation are exposed to low doses of radiation. Whereas the average effective dose used for patients in diagnostic procedures varies from $0.07 \mathrm{mSv}$ (e.g. chest radiography) to $9.3 \mathrm{mSv}$ (e.g. angiography) per examination, in 2001, the average annual effective dose (measured on the apron) in an interventional university hospital were $2.0 \mathrm{mSv}$ for physicians and $1.0 \mathrm{mSv}$ for nurses (UNSCEAR, 2008). In Japan, a study reported an annual mean effective dose to nurses in interventional radiology procedures to be around $1.34 \mathrm{mSv}$ (Chida et al, 20122013). Although there is an occupational dose exposure legal limit (currently $20 \mathrm{mSv} / \mathrm{year}$ ), this limit has been periodically reviewed and it has been historically decreased (Linet et al, 2010).

Radiosensitivity differs among cells. It depends on the type of tissue, cell cycle phase, among other factors. A cell group that is particularly vulnerable to radiation effects is the hematopoietic tissue (Dainiak, 2002; Hall, 2000). The existence of neurogenesis in the adult hippocampus and 
subventricular zone makes these cells also vulnerable to radiation (Prise and Saran, 2011; , Andres-Mach et al., 2008; , Eriksson et al., 1998; , Doetsch et al., 1999). Studies in rodents have shown that radiation doses compatible with therapeutic purposes triggered oxidative stress and altered memory in neonates (Caceres et al., 2010) and reduced/or suppressed neurogenesis in adults (Panagiotakos et al., 2007; Monje et al., 2002); on its turn, reduced neurogenesis has been correlated to hippocampus dependent cognitive tasks impairment (Rola et al., 2004,; Tada; et al Parent, 2000). These studies in rodents have used doses in the therapeutic range, which are higher than those used in diagnostic procedures. In humans, a possible link between neurodegeneration and ionizing radiation has been reviewed (Kempf et al, 2013). A systematic assessment of brain effects of chronic low dose radiation exposure is suggested to the interventional cardiology staff, a health team that is particularly exposed to higher doses of radiation during procedures (Picano et al, 2012).

However, most of the injuries due to radiation exposure are not specific to radiation (Muhkerjee and Mircheva, 1991), and it turns out difficult to recognize the origin of alterations at low dose exposure. As a health caregiver, the nursing team is exposed to a variety of occupational risk categories, such as physical (ergonomics, radiation, temperature), chemical (solvents, gases, antineoplastic agents), biological (bacteria, virus, spores) and psychosocial (stress, bullying, violence) risks (Moore and Moore, 2014). Previous studies have already shown DNA damage in lymphocytes of workers occupationally exposed to radiation; however, most of them included administrative employees as the control group, and not the unexposed health team (Bouraoui, et al., 2013; , Martinez et al., 2010; Maluf et al., 2001).

We wanted to test whether some biological markers, such as DNA damage, and some cognitive functions were affected in health workers exposed to an exposure dose within the recommended legal limit. So, the aim of this study was to compare the DNA damage of lymphocytes and the performance in cognitive tests of a nursing team occupationally exposed to ionizing radiation, within the annual legal dose limit (less than $20 \mathrm{mSv} / \mathrm{year}$ ), to a nursing team not exposed to radiation. 


\section{MATERIAL AND METHODS}

\subsection{Subjects}

This study was carried out at a University Hospital in Porto Alegre, RS, southern of Brazil. The estimation for the sample size considered a 0.7 correlation between the study factor and the outcome with a $80 \%$ power for a $5 \%$ significance (Maluf et al, 2001).

The sample consisted of a nursing team occupationally exposed $(n=38)$ or not to ionizing radiation (control group, $n=41$ ). They were all women, mean age of $45.24+8.80$ years, $67 \%$ were married, mean working time at the Institution was $16.01+10.66$ years $(n=79)$ and mean working time with ionizing radiation at the Institution was $13.21+10.74$ years $(n=38)$ (Table 1$)$. The exposed ones came from the Radiology $(n=22)$ and Hemodynamic $(n=16)$ Units; the nonexposed ones worked at the Ambulatory $(n=31)$ and Midwifery Units $(n=10)$ (Table 2), and they did not take part in radiation diagnostic procedures as employees in these Units. Briefly, the activities of the nursing team are described below. At the Ambulatory, the team provides assistance and educational guidance to the patients (children women, adult) and to their family; this may include home visit as well. The Midwifery Unit is part of a larger nursing service focused on the mother-child assistance (pregnancy, delivery and postpartum). Assistance in the Midwifery Unit is directed to an early interaction among mother, father, baby, and their family, promoting early breastfeeding. In the Radiology and Hemodynamics, besides the usual nursing activities, the nursing team is occupationally exposed to ionizing radiation diagnostic procedures. In the Radiology, the team may be exposed to computed tomography or conventional X-ray (with or without contrast agents), whereas in the Hemodynamics, they are exposed to conventional X-ray with the administration of contrast agent. Although the diagnostic procedures may last 15 to 30 minutes, the exposure time is much less than this and varies according to the procedure. The occupational exposed team makes use of personal protective equipment and attitudes. 
The subjects taking part of this study were asked about physical activities, smoking, alcohol and coffee drinking habits, and if they had been exposed to ionizing radiation due to diagnostic procedures (as patients) in the previous year. Their weigh and height were measured and the body mass index was calculated [weight, in $\mathrm{kg} /($ height, in meters)2]. The study protocol was approved by the ethics committee of the Hospital (\#11-0603) and all the participants that agreed to participate gave their written informed consent.

\subsection{Blood Sampling}

Peripheral blood samples of the exposed and control subjects were collected once into heparinized tubes, on Wednesdays, at 10 am to 4 pm, from January to May 2013. Blood sampling and processing of exposed and control donors were carried out simultaneously. All blood samples were coded, cooled and processed within a maximum $2 \mathrm{~h}$ period after collection. The alkaline Comet assay in whole blood samples was performed immediately after blood transportation.

\subsection{The Comet Assay}

The comet assay used in this study followed the general guidelines proposed by Singh et al (1988) and Fairbairn et al (1995) with some modifications. The alkaline version of comet assay allows evaluation of DNA damage in individual cells, including double and single strand breaks, alkali-labile sites, DNA-protein cross-links, and incomplete excision repair events (Burlinson et al., 2007). The true strand breaks, and/or the strand breaks formed as an intermediate step in excision repair of altered bases, lead to increase in DNA migration that is proportional to the extent of DNA damage. Every step of the assay was carried out under indirect light and the slides were coded and analyzed without knowledge of the sample identity. Volumes of $5 \mu \mathrm{L}$ of blood were added to $95 \mu \mathrm{L}$ of low melting point agarose, at $37^{\circ} \mathrm{C}$ and the mixtures were layered onto slides precoated with $1 \%$ normal agarose, covered with a coverslip, and left for 5 min at 4-8 ${ }^{\circ} \mathrm{C}$ to solidify. The coverslips were then removed carefully and the slides were immersed in a lysis solution (2.5 M NaCl, 100 mM EDTA, 10 mM Tris [pH 10], 1\% Triton X-100 and 10\% DMSO) for $1 \mathrm{~h}$. The alkaline comet assay was performed at $\mathrm{pH}$ 13. The positive control used 
was Hydrogen Peroxyde $(150 \mu \mathrm{M}) 5$ minutes. The slides were then placed in a horizontal gel electrophoresis tank. The unit was filled with fresh electrophoresis buffer (300 mM NaOH, 1 mM Na2EDTA, pH 13.0) and the slides were set in this alkaline buffer for 30 min to allow DNA unwinding and expression of alkali-labile sites. Denaturation and electrophoresis were performed at $4^{\circ} \mathrm{C}$ under dim light. Electrophoresis was carried out for $25 \mathrm{~min}$ at $25 \mathrm{~V}$ (300 mA). Slides were then neutralized (0.4 M Tris, $\mathrm{pH}$ 7.5), washed in double-distilled water and stained using a silver staining protocol as described in Nadin et al. (2001). After the staining step, gels were left to dry at room temperature overnight and analyzed using an optical microscope. One hundred cells of two replicate slides were randomly selected and analyzed blindly for DNA migration. Cells were visually scored according to tail length into five classes: (1) class 0: undamaged, without a tail; (2) class 1: with a tail shorter than the diameter of the head (nucleus); (3) class 2: with a tail length $1-2 \times$ the diameter of the head; (4) class 3 : with a tail longer than $2 \times$ the diameter of the head and (5) class 4: comets with no heads. Visual scoring of comets is considered a well-validated evaluation method by the International guidelines for comet assay as it is highly correlated with computer-based image analysis (Burlinson et al. 2007).

A value (damage index, DI) was assigned to each comet according to its class. Damage index ranged from 0 (completely undamaged: 100 cells $\times 0$ ) to 400 (with maximum damage: 100 cells $\times 4)$. The damage frequency, (DF, \%) was calculated based on the number of tailed versus tailless cells Collins (2004) and Collins et al. (2008).

\subsection{The CBMN test}

The cytokinesis-block micronucleus assay (CBMN test) was performed using the cytochalasin B technique described by Fenech and Morley, (1985) and following recommendations from the International Collaborative Project on Micronucleus Frequency in Human Populations (HUMN Project) to measure micronuclei, nucleoplasmic bridges, and nuclear buds in untreated cells. The cultures were set up in duplicate as $500 \mu \mathrm{l}$ cultures at $1 \times 106$ cells $/ \mathrm{mL}$, in Gibco PB-MAX Karyotyping medium (Life technologies, Grand Island, New York, USA) supplemented with $10 \%$ fetal bovine serum. Lymphocytes were incubated at $37^{\circ} \mathrm{C}$ with $5 \% \mathrm{CO} 2$. At 44 hours after initiation, cells were blocked in cytokinesis by adding cytochalasin B (Sigma, St. Louis, MO; 
final concentration, $4 \mu \mathrm{g} / \mathrm{mL}$ ). The total incubation time for all cultures was 72 hours. After incubation, the cells were fixed in 3:1 methanol/glacial acetic acid, dropped onto clean microscopic slides, air-dried, and stained with Giemsa stain. For each sample, 1.000 binucleated cells were scored blindly using optical microscope following the scoring criteria outlined by HUMN Project (Fenech et al., 2003; , Fenech, 2002, 2007); the numbers of micronuclei, nucleoplasmic bridges, and nuclear buds per 1,000 binucleated cells were recorded. In addition, a minimum of 500 cells was also scored to determine the percentage of cells with 1, 2, 3 and $>4$ nuclei. A nuclear division index (NDI) was calculated as per the formula NDI $=(\mathrm{M} 1+2 \mathrm{M} 2+$ $3 \mathrm{M} 3+4 \mathrm{M} 4) / \mathrm{n}$; M1 to M4 indicates the number of cells with one to four nuclei, respectively, and $\mathrm{n}$ is the number of cells scored.

\subsection{Cognitive Tests}

The cognitive tests were applied in a silent room without external interference or interruption. The tests were applied by previously trained master students (IB and APSB). The Stroop test was applied to score selective attention, whereas the digit and word span to score memory (in: Strauss et al., 2006). Briefly, the Stroop test consists of 3 sets of stimuli, each in a time frame of 45 seconds: first, the person must read colored words that match with the colors of the ink (Stroop_word); second, she reads the color of colored X's (Stroop_word); and third, she reads the unmatched color of the written color word (Stroop_color/word). There is an increase in time reaction in the last stimuli due to the interference of the word on the incongruent color, and it varies according to age and gender (MacLeod, 1991; , Alvarez and Emory, 2006). The digit and word span are components of the Wechsler scale that is commonly used to access declarative and working memory. In the digit span test, the subject repeats a crescent sequence of digits (maximum 14) said by the examiner. In the word span test, the subject is asked to repeat a list of (10) words said previously by the examiner. 


\subsection{Total Accumulated Occupational Dose}

The exposed team was monitored by termoluminescent dosimeters (TLD) worn on the lead apron during work shift. The monthly/annual doses were reported by the institution from the measurement of each employee's dosimeter. The total accumulated occupational dose of radiation was obtained by adding all annual doses for each occupationally exposed employee during the entire period of work in the Hospital. The nonexposed subjects did not make use of dosimeters.

\subsection{Data Analysis}

The variance homogeneity of the data was checked using the Kolmogorov-Smirnov test. In case of nonhomogeneity, the variables were mathematically transformed (square root) to allow homogeneity.

Exposed $x$ Nonexposed: The total accumulated occupational dose of radiation was the independent variable. Lymphocyte DNA DI and DF, MN and NDI were the dependent variables. The variables DI and DF were analyzed using the independent t-student test, and the group exposed occupationally to radiation was compared to the nonexposed group. The following variables of these two groups, sqr (square root) of MN, and NDI were analyzed by the one way ANOVA, considering age as a covariable (Palazzo; and Maluf, 2011). For the exposed ones, Spearman or Pearson test was used to analyze correlation between MN, the occupational dose of radiation - obtained from last month, last year, and the total accumulated dose, the Stroop test, the digit and word span test and the years of education.

An additional one way ANOVA was done to compare the data among the four Units: Radiology, Hemodynamics, Ambulatory and Midwifery Unit. When applicable, a Bonferroni post hoc test was used. 


\section{RESULTS}

The characteristics of the nursing team studied are shown in Tables 1 and 2.

Table 1 - Sociodemographic and Professional Characteristics of the Nursing Team in a Hospital in Southern Brazil

\begin{tabular}{|c|c|c|c|}
\hline $\begin{array}{l}\text { Sociodemographic and Professional } \\
\text { Characteristics }\end{array}$ & Mean \pm SD & $\mathbf{N}$ & $\%$ \\
\hline Age (years) & $45.24 \pm 8.80$ & 79 & \\
\hline Gender (female) & & & 100 \\
\hline \multicolumn{4}{|l|}{ Marital Status } \\
\hline Single & & 26 & 32.9 \\
\hline Married & & 53 & 67.1 \\
\hline \multicolumn{4}{|l|}{ Profession / Education } \\
\hline Registered Nurse (Superior) & & 14 & 17.72 \\
\hline Nurse Assistant (High School) & & 65 & 82.28 \\
\hline \multicolumn{4}{|l|}{ Years of Work } \\
\hline In the Institution: & $16.01 \pm 10.66$ & 79 & 100 \\
\hline With ionizing radiation & $13.21 \pm 10.74$ & 38 & 48.1 \\
\hline (exposed group) & & & \\
\hline
\end{tabular}

Table 2 - Professional Categories Distribution of the Nursing Team Sample

\begin{tabular}{ccccc}
\hline & \multicolumn{2}{c}{ Exposed } & \multicolumn{2}{c}{ Non Exposed } \\
\hline & Radiology & Hemodynamics & Midwifery Unit & Ambulatory \\
\hline Nurse & 2 & 6 & 2 & 4 \\
Nurse Assistant & 20 & 10 & 8 & 27 \\
\hline
\end{tabular}


The results of the comet assay and CBMN assay from the nursing team occupationally exposed to low dose and non-exposed to ionizing radiation are shown in Table 3. In graph 1, the results are shown separately for each of the four Units.

Table 3. Lymphocytes DNA damage in the Nursing Team, according to Radiation Exposure Condition

\begin{tabular}{lcc}
\hline & $\begin{array}{c}\text { Exposed } \\
n=38\end{array}$ & $\begin{array}{c}\text { Control } \\
n=41\end{array}$ \\
\hline DI & $58.12 \pm 46.30$ & $69.66 \pm 40.38$ \\
DF & $35.92 \pm 21.17$ & $42.81 \pm 17.44$ \\
MN & $2.41 \pm 1.96$ & $2.44 \pm 1.83$ \\
NDI & $1.88 \pm 0.14$ & $1.88 \pm 0.17$ \\
Total Accumulated Dose (mSv) & $5.72 \pm 4.09$ & - \\
Age (years) & $45.05 \pm 8.79$ & $45.41 \pm 8.90$
\end{tabular}

Abbreviations: $D I=$ damage index; $D F=$ damage frequency $M N=$ micronucleus frequency, $N D I=$ nuclear division index; $m S v$ : milisievert. Values are expressed as mean $\pm s d$.

No difference was found for DI, DF, MN, and NDI between the occupationally exposed and non-exposed groups (Table 3). However, when the groups were analyzed separately and independently of the occupationally radiation exposure condition, some differences emerged for DI and DF (Graph 1). In Hemodynamics, DI $(39.98$ + 33.38) was found to be lower when compared to all other 3 Units: in Radiology [(71.33 + 50.48), p=0.035], Ambulatory [(55.70 + 28.74), $\mathrm{p}=0.001]$ and Midwifery Unit [(112.95 + 41.74), p=0.000]. In Hemodynamics, DF (26.33 
+ 15.55) was also lower when compared to Radiology [(42.90 + 22.27), $\mathrm{p}=0.042]$ and Midwifery Unit [(59.16 + 15.72), p=0.000]. The DF in Midwifery Unit $(112.95+41.74)$ was higher than in Ambulatory [ $(55.70+28.74), \mathrm{p}=0.009]$. No difference was found for rqMN, or NDI among the four Units. The (sqr) total accumulated dose was not different between the Hemodynamics and Radiology.

Graph 1. Lymphocytes DNA damage in the Nursing Team of the Radiology, Hemodynamics, Ambulatory and Midwifery Units

\section{DNA Damage Index and Frequency in Lymphocytes of the Nursing Team}

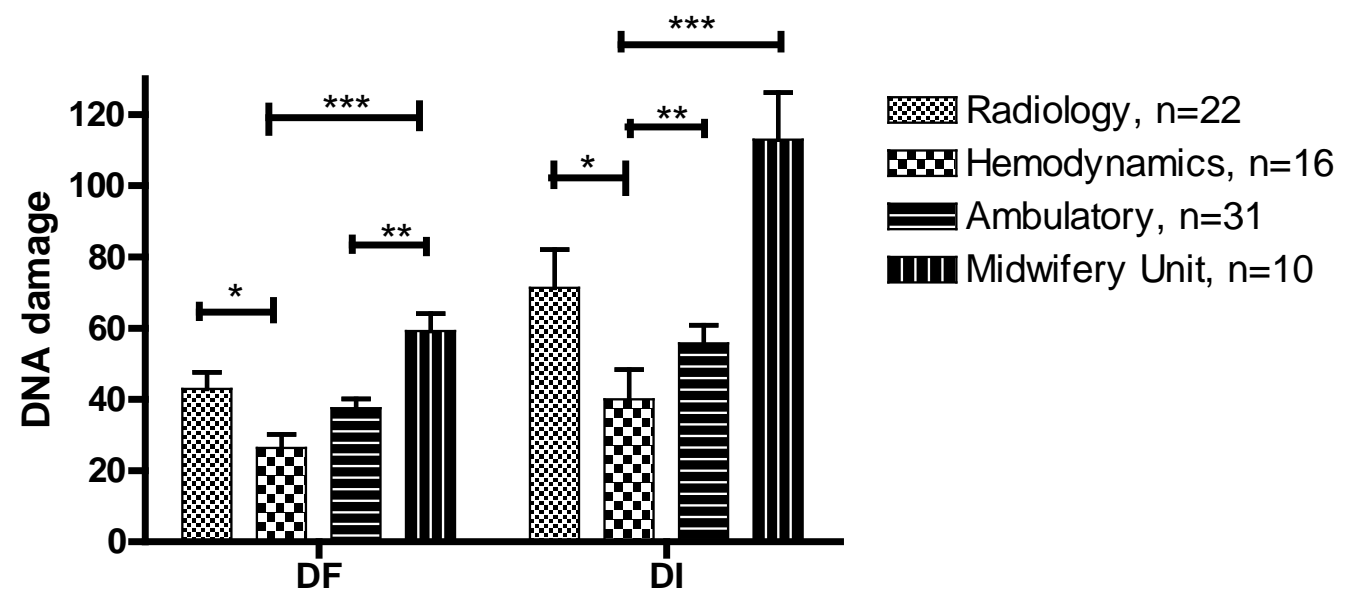

Abbreviations: $D I=$ damage index; $D F=$ damage frequency. Values are expressed as mean \pm sd. * $(p<0.05) ; * *(p<0.01) ; * * *(p=0.000)$.

Almost all subjects in the studied group were nonsmokers, the majority did not consume alcohol, and when they did, it was in small quantities. Most of them did not practice physical exercises. No difference was found for DI, DF, MN and BMI according to their smoking, alcohol consuming and physical exercise habits (Table 4). 
Table 4: Lymphocytes DNA Damage according to Smoking, Alcohol consuming and Physical Exercise Habits of the Nursing Team

\begin{tabular}{lllllll}
\hline & \multicolumn{2}{c}{ Smoker } & \multicolumn{2}{c}{ Alcohol } & \multicolumn{2}{c}{ Physical Exercise } \\
\cline { 2 - 7 } $\mathrm{N}=$ & \multicolumn{1}{c}{ Yes } & No & Yes & No & Yes & \multicolumn{1}{c}{ No } \\
79 & \multicolumn{1}{c}{4} & \multicolumn{1}{c}{75} & \multicolumn{1}{c}{28} & \multicolumn{1}{c}{51} & \multicolumn{1}{c}{21} & 58 \\
\hline DI & $81.20 \pm 70.99$ & $63.20 \pm 42.05$ & $63.20 \pm 49.13$ & $64.62 \pm 40.49$ & $65.58 \pm 44.86$ & $63.58 \pm 43.30$ \\
DF & $46.58 \pm 29.78$ & $39.12 \pm 19.04$ & $38.47 \pm 23.05$ & $40.07 \pm 17.50$ & $39.64 \pm 20.87$ & $39.45 \pm 19.19$ \\
MN & $5.00 \pm 4.24$ & $4.77 \pm 3.78$ & $4.32 \pm 3.64$ & $5.04 \pm 3.86$ & $5.14 \pm 4.30$ & $4.66 \pm 3.60$ \\
BMI & $26.83 \pm 5.27$ & $28.20 \pm 4.69$ & $28.12 \pm 4.93$ & $28.14 \pm 4.61$ & $27.50 \pm 4.50$ & $28.35 \pm 4.78$ \\
\hline
\end{tabular}

Abbreviations: $D I=$ damage index; $D F=$ damage frequency; $M N=$ frequency of micronucleus; $B M I=$ body mass index. Values are expressed as mean $\pm s d . \chi^{2}$ test.

No significant correlation was found between MN and the occupational dose of radiation from last month, last year, or the total accumulated dose. On the other hand, MN was negatively correlated to years of education $(r=-0.338$; $p=0.038$; $n=38)$, negatively correlated to either the Stroop_word score $(r=-0.532 ; p=0.001 ; n=38)$ and Stroop_color score $(r=-0.332 ; p=0.042$; $\mathrm{n}=38$ ). The correlation between DI and the Stroop_color/word test did not reach significance, although a trend toward a negative correlation was found $(r=-0.294 ; p=0.073 ; n=38)$. Years of education were positively correlated to the score obtained in Stroop_color/word test $(r=+0.398$; $\mathrm{p}=0.013 ; \mathrm{n}=38)$ and digit span $(\mathrm{r}=+0.497 ; \mathrm{p}=0.002 ; \mathrm{n}=38)$. Whereas a negative correlation was found between the digit span score and DI ( $\mathrm{r}=-0.340 ; \mathrm{p}=0.037 ; \mathrm{n}=38$ ), a positive correlation was found between digit span score and the last year dose $(r=+0.424 ; p=0.008$, $\mathrm{n}=38)$.

\section{DISCUSSION}

The present study did not show differences in lymphocyte DNA damage in a female nursing team occupationally exposed to ionizing radiation when compared to a nursing team not exposed to it. The radiation doses of the exposed ones were all within the allowed legal annual dose 
limits. This kind of exposure is accepted as a low dose exposure. The lack of significance could be attributed to the difficulty in finding effects in a low dose situation, and to the relatively small number of subjects investigated. On the other hand, other studies did show increased DNA damage in a health team occupationally exposed to radiation. However, the control group was formed by administrative employees, and not an unexposed nursing team (Bouraoui et al., 2013,; Martinez et al., 2010; Maluf et al., 2001). An increase in DNA damage was also shown after a workday for those in an occupational radiation exposure status when compared to unexposed administrative employees, in a health institution (Martinez et al 2010). The exposed employees from the Radiology, Nuclear Medicine and Radiotherapy Departments increased DNA fragmentation after the workday, although differently among the Departments. Those working in Nuclear Medicine and Radiotherapy, Departments, where the monthly radiation exposure dose were higher, displayed a longer comet tail length than those in Radiology. A positive correlation between monthly radiation dose and length of the DNA tail migration was also shown before and after the workday (Martinez et al., 2010).

In the current study, no correlation was found between DNA damage index or the micronucleus frequency in lymphocytes, and the radiation exposure dose from any of the previous months up to a year before blood sampling, neither with the total previous annual dose, nor with the years of occupational radiation exposure. It is worth emphasizing that the comet assay evaluates DNA damage primarily to recent exposures, such as minutes to hours, and micronucleus evaluates older exposures (days to months). Unfortunately, we did not measure daily exposure doses.

It was hypothesized that the chronic exposure to ionizing radiation could potentially impair cognitive functions, such as attention and memory. However, no correlation was found between the scores of the Stroop test and word span, and the radiation doses. HoweverNonetheless, the relation found between DNA damage (DI, DF, MN) and cognitive results support the idea that as higher the damage, the worse is the cognitive performance in attention and memory. So, the present results suggest that the low exposure doses are not linked to DNA damage and cognitive impairment. Surprisingly, a significant positive correlation was found between the last year exposure dose and the digit span score. This finding could mean a positive consequence for a low chronic exposure to radiation, such as considered in hormesis, since a higher score in digit 
span represents a better result for the working memory cognitive function. Mechanisms such as the bystander effect and adaptive response may be relevant and underlie the favorable response at low doses (Brooks and Dauer 2014). This result is opposite to our original hypotheses. We expected a worse memory performance after chronic exposure, since hippocampus is a radiosensitive area. Caution must be taken when interpreting this isolated result.

Nonetheless, mechanisms such as the bystander effect and adaptive response may be relevant and underlie the favorable response at low doses (Brooks and Dauer, 2014).

When the DNA damage data was analyzed separately, according to the working Units, another finding was shown. The Hemodynamic Unit had the lowest DNA damage index when compared to all other Units, whereas the Midwifery Unit had a higher damage index when compared to the Hemodynamic. This was unexpected, since the Midwifery Unit belonged to the unexposed control group.

Ionizing radiation is not the only agent that can damage the DNA. Reactive oxygen species production may be increased not only by gamma or x-radiation, but also by inflammation, smoking air pollution, ultraviolet radiation, chemotherapy (Reuter, 2010) and stress (Andersen and; Teicher, 2004; , Bremner et al., 2003,; McEwen, 2008; , Pruessner et al., 2010). What was supposed to be the control group in this study was the unexposed nursing team. Instead, we did find increased damage even within the unexposed group. It is worth noting that most of other studies investigating the radiation effects included administrative personal, and not the health team. It raises the possibility that agents other than radiation are damaging the DNA of the nursing team. Only 4 individuals in 79 were smokers in this sample, so smoking would hardly be a factor. Neither drinking alcohol nor the physical activity influenced the result. The constant exposure to infectious agents, or stress, could be some alternatives and are subject of our ongoing study.

The absence of increased damage within the exposed group is in fact an advantage, and may mean an effective radioprotection attitude by the group, such as proper shielding and distance, less exposure frequency and duration (e.g. staff rotation). The doses used in Hemodynamic Units are usually higher than, for example, in Radiology. However, we did not find statistical 
differences between them. Another possibility, although still controversial, is the hormesis effect, a favorable response to a chronic low exposure. Nonetheless, it must be kept in mind that even not finding damage in lymphocytes does not mean that other radiosensitive tissues that could not be investigated in human research were spared.

The mean educational level of the nursing team was not different among the four Units. Years of education were negatively correlated to the micronucleus frequency and to the accumulated radiation dose. In other words, the lower the educational level, the higher the damage and the accumulated dose of radiation. This result may raise different interpretations. In Brazil, the nursing team is composed by a registered nurse (Universitary degree), nurse technicians and assistants (high school). According to the category, the exposure to risks may differ. The closeness and time spent in patient assistance by nurse technicians and assistants are generally higher than by nurses. Both distance and time are important factors in radioprotection. Another possible explanation is that the better cognitive performance by higher education level may improve the awareness of risks at work, and so attitudes toward radioprotection may be optimized, such as proper shielding, distance from sources of radiation, and less time of exposure. This safer behavior could cause less damage and lower micronucleus frequency and total accumulated dose. Cognitive decline may be an important predictive risk factor for safety at work (Dodman, Agius and Turner,et al 2012; , Allhavari et al, 2014). The impact of cognitive impairment on accidents and unsafe behaviors was found to be stronger for those who are relatively deficient in consciousness (Wallace and Vodanovich, 2003). However, the relation may be more complex, where a lower educational level may picture a more unfavorable social and economical status, with lower income, higher workload in multiple jobs and/or exposure to other risk factors that could cause damage. This damage could in its turn be responsible for a worse cognitive performance and perpetuate risk exposures and damage.

This study has some limitations. The dose of exposure considered in this study refers to the occupational dose reported by the hospital for their employees, while working in their respective Units; we had no access to any other dose report in case some of them worked in a situation of ionizing radiation exposure, during the study or in the past, in a second job. So, the doses in this study may be underestimated. Both groups, occupationally exposed and occupationally non- 
exposed, have been partially exposed to diagnostic radiation procedures as patients (30 and 25 exposure procedures, respectively) in the previous year. The increasing number of this kind of procedures in the general population may interfere with long term results, particularly to increased $\mathrm{MN}$ frequency.

In summary, the results of the present study have shown that the occupational radiation exposure condition did not increase DNA damage in the nursing team. In fact, other factors may be relevant to DNA damage in this professional team and are subject of ongoing study. 


\section{REFERÊNCIAS}

ALVAREZ, J.A.; EMORY, E. Executive Function and the Frontal Lobes: A Meta-Analytic Review. Neuro Rev, 16 No. 1, 2006.

ANDERSEN, S. L.; TEICHER, M.H. Delayed effects of early stress on hippocampal development Neuropsychopharmacology, 29, 1988 - 1993, 2004.

ANDRES-MACH, M.; ROLA, R.; FIKE, J. Radiation effects on neural precursor cells in the dentate gyrus Cell Tissue Res, 331, 251 - 262, 2008.

BEIR, VII. 2006 Health risks from exposure to low levels of ionizing radiation. BEIR VII phase, 2 .

BOURAOUI, S.; MOUGOU, S.; DRIRA, A.; TABKA, F.; BOUALI, N.; MRIZEK, N.; ELGHEZAL, H.; SAAD, A. A cytogenetic approach to the effects of low levels of ionizing radiation (IR) on the exposed tunisian hospital workers. Int J Occup Med Environ Health, 26, $144-154,2013$.

BRENDLER-SCHWAAB, S.; HARTMANN, A.; PFUHLER, S.; SPEIT, G. The in vivo comet assay: use and status in genotoxicity testing. Mutagenesis, 20, 245 - 54, 2005.

BRENNER, D.J. Cancer risks attributable to low doses of ionizing radiation: assessing what we really know. Proceedings of the National Academy of Science of the United States of America. 100, 13761 - 13766, 2003.

BROOKS, A.; LAWRENCE, D. Radiation Dosimetry and Risk in the Practice of Nuclear Medicine. Advances in Radiation Biology: Effect on Nuclear Medicine, 44, 179 - 186, 2014. 
CACERES, L. Hippocampal-related memory deficits and histological damage induced by neonatal ionizing radiation exposure. Role of oxidative status. Brain Res, 1312, 67 - 78, 2009.

COLLINS, A.R.; OSCOZ, A.A.; BRUNBORG, G.; GAIVÃO, I.; GIOVANNELLI, L.; KRUSZEWSKI, M.; SMITH, C.C.; STETINA, R. The comet assay: topical issues. Mutagenesis, 23, $143-$ 51, 2008.

COLLINS, A.R. The cometa assay for DNA damage and repair: principles, applications and limitations. Mol Biotechnol, 26, 249 - 261, 2004.

DAINIAK, N. Hematologic consequences of exposure to ionizing radiation. Exp Hematol, 30, 513-528, 2002.

DOETSCH, F.; GARCÍA-VERDUGO, J.M.; ALVAREZ-BUYLLA, A. Regeneration of a germinal layer in the adult mammalian brain. Proc Natl Acad Sci USA, 96, 11619 - 11624, 1999.

ERIKSSON, P.S. et al. Neurogenesis in the adult human hippocampus. Nat Med, 4, 1313 1317, 1998.

FAIRBAIRN, D.W.; OLIVE, P.L.; O'NEILL, K.L. The comet assay: a comprehensive review. Mutat Res, 339, 37 - 59, 1995.

FENECH, M. Cytokinesis-block micronucleus cytome assay. Nat Protoc, 2, 1084 - 1104, 2007. FENECH, M. Molecular mechanisms of micronucleus, nucleoplasmic bridge and nuclear bud formation in mammalian and human cells. Mutagenesis, 26, 125 - 132, 2011. 
FENECH, M. Chromosomal biomarkers of genomic instability relevant to cancer. Drug Discov Today, 7, $1128-1137,2002$.

FENECH, M.; CHANG, W.P.; KIRSCH-VOLDERS, M.; HOLLAND, N.; BONASSI, S.; ZEIGER, E. HUMAN project: detailed description of the scoring criteria for the cytokinesisblock micronucleus assay using isolated human lymphocyte cultures. Mutat Res, 534, 65 - 75. 2003

FENECH, M.; MORLEY, A.A. Measurement of micronuclei in lymphocytes. Mutat Res, 147, $29-36$.

HALL, E.J. Radiobiology for the radiologist. 1985.

LIAO, W.; MCNUTT, M.A.; ZHU, W.G. The comet assay: a sensitive method for detecting DNA damage in individual cells. Methods, 48, 46 - 53, 2009.

MACLEOD, C.M. Half a century of research on the Stroop effect: an integrative review. Psychological Bulletin, 109, 163 - 203, 1991.

MALUF, S.W.; PASSOS, D.F.; BACELAR, A.; SPEIT, G.; ERDTMANN, B. Assessment of DNA damage in lymphocytes of workers exposed to X-radiation using the micronucleus test and the comet assay. Environ Mol Mutagen, 38, 311 - 315, 2001.

MARTÍNEZ, A.; COLEMAN, M.; ROMERO-TALAMÁS, C.A.; FRÍAS, S. An assessment of immediate DNA damage to occupationally exposed workers to low dose ionizing radiation by using the comet assay. Rev Invest Clin, 62, 23 - 30, 2010. 
MCEWEN, B.S. Allostasis, allostatic load, and the aging nervous system: role of excitatory amino acids and excitotoxicity. Neurochem Res, 25, 1219 - 1231, 2008.

MONJE, M.L.; MIZUMATSU, S.; FIKE, J.R.; PALMER, T.D. Irradiation induces neural precursor-cell dysfunction. Nat Med, 8, 955 - 962, 2002.

MOORE, P.V.; MOORE, R.L. Fundamentals of Occupational and Environmental Health Nursing. 2014.

NADIN, S.B.; VARGAS-ROIG, L.M.; CIOCCA, D.R. A silver staining method for single-cell gel assay. J Histochem Cytochem, 1, 180 - 93, 2011.

PALAZZO, R.P.; MALUF, S.W. Técnica de micronúcleos com bloqueio da citocinese celular. Citogenética Humana, 180 - 193, 2011.

PANAGIOTAKOS, G. Long-term impact of radiation on the stem cell and oligodendrocyte precursors in the brain. PLoS One, 2, 588, 2007.

PRISE, K.M.; SARAN, A. Concise review: stem cell effects in radiation risk. Stem Cells, 29, $1315-1321,2011$.

PRUESSNER, J.C.; DEDOVIC, K.; PRUESSNER, M.; LORD, C.; BUSS, C.; COLLINS, L. Stress regulation in the central nervous system: evidence from structural and functional neuroimaging studies in human populations. Psychoneuroendocrinology, 35, 179 - 191, 2010.

REUTER, S.; GUPTA, S.C.; CHATURVEDI, M.M.; AGGARWAL, B.B. Oxidative stress, inflammation, and cancer: How are they linked? Free Radic Biol Med, 49, 1603 - 1616, 2010. 
ROLA, R.; RABER, J.; RIZK, A.; OTSUKA, S.; VANDENBERG, S.R.; MORHARDT, D.R.; FIKE, J.R. Radiation-induced impairment of hippocampal neurogenesis is associated with cognitive deficits in young mice. Exp Neurol, 188, 316 - 330, 2004.

ROPOLO, M.; BALIA, C.; ROGGIERI, P.; LODI, V.; NUCCI, M.C.; VIOLANTE, F.S.; SILINGARDI, P.; COLACCI, A.; BOLOGNESI, C. The micronucleus assay as a biological dosimeter in hospital workers exposed to low doses of ionizing radiation. Mutat Res, 747, 7 13, 2012.

SINGH, N.P.; MCCOY, M.T.; TICE, R.R.; SCHNEIDER, E.L. A simple technique for quantitation of low leves of DNA damange in individual cells. Exp Cell Res, 175, 184 - 191, 1988.

STRAUSS, E.; SHERMAN, E.M.S.; SPREEN, O.A. Compedium of neuropsychological tests. 2006.

TADA, E.; PARENT, J.M.; LOWENSTEIN, D.H.; FIKE, J.R. X-irradiation causes a prolonged reduction in cell proliferation in the dentate gyrus of adult rats. Neuroscience, 99, 33 - 41, 2000.

UNSCEAR (United Nations Scientific Committee on Effects of Atomic Radiation). Sources and effects of ionizing radiation. 2008 